\title{
NEW RESULTS ON SEXUAL DIFFERENCES IN TARSAL ADHESIVE SETAE OF DIABROTICA VIRGIFERA VIRGIFERA LECONTE (COLEOPTERA, CHRYSOMELIDAE, GALERUCINAE)
}

\author{
KAI GLOYNA ${ }^{1}$, THOMAS THIEME ${ }^{1}$, STANISLAV GORB ${ }^{2,3}$, \\ and DAGMAR VOIGT2,3,4,* \\ ${ }^{1}$ BTL Bio-Test Labor GmbH Sagerheide, Birkenallee 19, D-18184 Sagerheide, Germany \\ 2 Max-Planck Institute for Metals Research, Evolutionary Biomaterials Group, Department of Thin-Films and Biological Systems, \\ Heisenbergstraße 3, D-70569, Stuttgart, Germany \\ ${ }^{3}$ Department of Functional Morphology and Biomechanics, Zoological Institute, Christian-Albrechts-Universität zu Kiel, Am \\ Botanischen Garten 1-9, D-24098 Kiel, Germany \\ ${ }^{4}$ Present address: Botanical Institute, Technische Universität Dresden, D-01062 Dresden, Germany \\ * Corresponding author: dagmar.voigt@tu-dresden.de
}

\section{ABSTRACT}

Previous light microscopy studies revealed a hairless patch on the feet of male Diabrotica virgifera virgifera. However, in related species of chrysomelid beetles the males have special adhesive setae with discoid terminals, which adhere to the elytra of females during copulation. In the present study, we examined the pretarsi of $D$. virgifera virgifera at a high magnification using scanning electron microscopy. The distinct sexual tarsal dimorphism in this species is confirmed. However, our results do not support the presence of a hairless patch on the feet of males, but a field of densely-packed male-specific adhesive setae with discoid terminals.

Keywords: attachment system, mating, morphology, sexual dimorphism, western corn rootworm

\section{Introduction}

The chrysomelid beetle Diabrotica virgifera virgifera LeConte is native to Northern America and an invasive pest in Europe where it causes serious economic damage to maize crops. Both adults (beetles) and larvae attack maize, but the main economic losses are caused by the damage inflicted by larvae feeding on the roots. D. virgifera virgifera was first recorded in Europe in a Serbian maize field in 1992 (Baca 1993). The species spread rapidly having a potentially wide range of host plants other than maize (Möser 2003; Breitenbach et al. 2006). Currently, D. virgifera virgifera occurs in a wide area of Europe, having colonized Germany starting in Bavaria in 2007 and reaching Hessen in the North and Saxony in the East by 2012 (Baufeld 2014). Spread, establishment and subsequent economic effects of $D$. virgifera virgifera depend on the availability of maize and are favoured by non-rotated maize production (Kehlenbeck 2014).

If no action is taken by farmers to suppress the Diabrotica population, yield losses of up to $70 \%$ are reported, although typically most fields suffer an estimated 30\% loss (Commision Staff Working Document 04-02-1012).

The present experience based on extensive monitoring programs shows that the measures for the eradication of isolated outbreaks in place since 2003 are effective, if properly applied. Still, available data suggests that the infested zone keeps on expanding and therefore it is expected that with the present regulatory framework the pest will eventually become established in all the areas in the EU where maize is cultivated. Therefore $D$. virgifera virgifera was withdrawn from the list of regulated harm- ful organisms (Commission Implementing Directive 2014/19/EU)

For different purposes, simple and fast methods of identifying the sexes of this beetle are essential. So far, sexes in D. virgifera virgifera are distinguished by tubercles on the tip of the abdomen of the pupae of females. Adults differ from each other in (1) elytral patterns (males black, females striped, but opposite forms occur), (2) the shape of the abdominal tip (blunt in males with supra-anal plate, pointed in females), (3) longer antennae in males (but males with relatively short antennae or females with relatively long antennae occur), (4) the number and shape of antennal sensilla, (5) the slightly, but distinctly longer antennal joint III in females and joint II in males (Krysan 1986).

In this context, there are differences in the basitarsal morphology of males and females of $D$. virgifera virgifera that can be seen using light microscopy (Bechyné 1956; Hammack and French 2007). Sexual tarsal dimorphism is common in Chrysomelidae and previously reported in several species closely related to $D$. virgifera virgifera belonging to the subfamily Galerucinae, Galerucella tenella L., Lochmaea caprea L., Lochmaea suturalis Thomson and Sermylassa halensis L. (Stork 1980). In these species, males have special setae with discoid terminals, which they use to grip the elytra of females during copulation. $\mathrm{Al}$ though male $D$. virgifera virgifera are also firmly attached to the elytra of females during copulation only a hairless planar ovoid patch proximal to the first tarsomere has been described so far for this species (Hammack and French 2007), which was recently called an adhesive disk (Prado 2013).The surface structure of the hairless patch 
is similar to that of compound eyes consisting of round, hexagonal or octagonal facets, which appear slightly concave in the centre, but not very chitinized (Bechyné 1956).

Thus, it is interesting to know how males attach themselves to females in D. virgifera virgifera. Do males, like those of related species, differ from females in the arrangement and/or shape of adhesive setae on their feet? Do they possess a different tarsal morphology compared to other species of Galerucinae previously studied?

To answer these questions, we used scanning electron microscopy to visualize the attachment system of $D$. virgifera virgifera at a high resolution.

\section{Materials and Methods}

Test insects of two different origins were used: a non-diapausing strain (USDA-NCARL, Brookings, USA; Branson 1976) reared since 2006, and a diapausing strain from Northern Italy. The rearing-methods are those described by Branson et al. (1975) and Jackson (1986). Larvae were reared on maize seedlings cv. Tassilo (KWS Saat AG, Einbeck, Germany) and adult beetles were fed fresh leaves of young maize plants, maize pollen and combs, zucchini, and pieces of apple, lettuce and water. The Diabrotica strains were reared in isolated rooms registered for quarantine proposes.

Tarsi of dead dry beetles were cut off using a razor blade, mounted with the ventral side up on metal sample holders using double-sided sticky carbon tape, sputtered with gold-palladium $(6 \mathrm{~nm})$ and examined in a scanning electron microscope (SEM) Hitachi S-4800 at $5.0 \mathrm{kV}$ (Hitachi High-Technologies Corp., Tokyo, Japan). Based on the micrographs obtained the arrangement and shape of the adhesive setae was described.

\section{Results}

The tarsi of male and female D. virgifera virgifera consist of five tarsomeres, with perpendicular claws distally (Fig. 1). All tarsomeres are covered with setae. Four types of adhesive setae of different shapes and sizes occur on the first, second, and third tarsomeres (Fig. 2). Obviously, the distribution of setae varies depending on tarsomere and leg. Filamentous, lanceolate and spatula-shaped setae are present in both females and males, but short mushroom-shaped setae with discoid terminals are present only in males on the first tarsomere of the fore- and mid-legs (Fig. 1, 2). The shape of these male-specific setae seems to be concave, long setae surround short setae in the middle of the tarsomeres. Due to the high density per unit area of these setae the shape of the discoid plates appears hexagonal. Moreover, male setae are hexagonally arranged, with a higher number on the fore-tarsi than the mid-tarsi. Spatula-shaped setae only occur on the third tarsomeres of each leg of both females and males, whereas lanceolate and filamentous setae occur on each tarsomere of each leg.

\section{Discussion}

Hairy attachment systems have evolved independently in different groups of animals enabling them to walk upside down on plants, ceilings, walls and smooth surfaces (e.g. Stork 1980, 1983; Pelletier and Smilowitz 1987; Gorb 2001, 2005). Tarsal adhesive setae have a wide range of different structures even on different parts of a single tarsus, depending on their function, temporal length of adhesion and adhesive strength generated (Stork and Evans 1976). Our results indicate a distinct sexual dimorphism in tarsal adhesive setae in D. virgifera virgifera, which is in accordance with previous descriptions of various chrysomelid species (Stork 1980). Thus, recent reports of a hairless planar ovoid patch on male tarsomeres (Hammack and French 2007) are refuted. SEM micrographs clearly show an area of male-specific adhesive setae with discoid terminals on proximal basitarsomeres of fore- and mid-legs, but not on hindlegs. The "compound-eye similar surface structures" of male-specific hairless patches on tarsi, previously observed by Bechyné (1956), corresponding to the hexagonal arrangement and close packing of male adhesive setae, are clearly seen in SEM photographs.

Probably, these morphological modifications of the feet of males correspond to the microstructure of female elytra and are an adaptation for adhering to the elytral surface of females during copulation. Such adaptations have been previously discussed for other species of beetle (Aiken and Khan 1992; Bergsten et al. 2001; Miller 2003; Voigt et al. 2008: Leptinotarsa decemlineata Say, Chrysomelidae; Karlsson Green et al. 2013: Dytiscidae). In males of $D$. virgifera virgifera the specialized mushroom-shaped adhesive tarsal hairs arranged concavely in oval areas on the first tarsomeres of their fore- and midleg, which usually contact the elytra surface of females, are probably an adaptation for attaching to the convex elytra of females. This functional explanation, however, does not conform with previous observations of mating posture and behaviour (Lew and Ball 1979).

Spatula-shaped setae, in particular, may enable them to adhere to plant substrates. This has been previously suggested as the way they adhere to rough substrata, such as plants, as the presence of spatula-shaped thin tips of setae provide an optimum means of adapting to the form of the substrate due to the low bending stiffness of the spatulate plate (Persson and Gorb 2003; Voigt et al. 2008).

\section{Conclusion}

D. virgifera virgifera is distinctly sexually dimorphic in terms of the shape of its tarsal adhesive setae. Different 

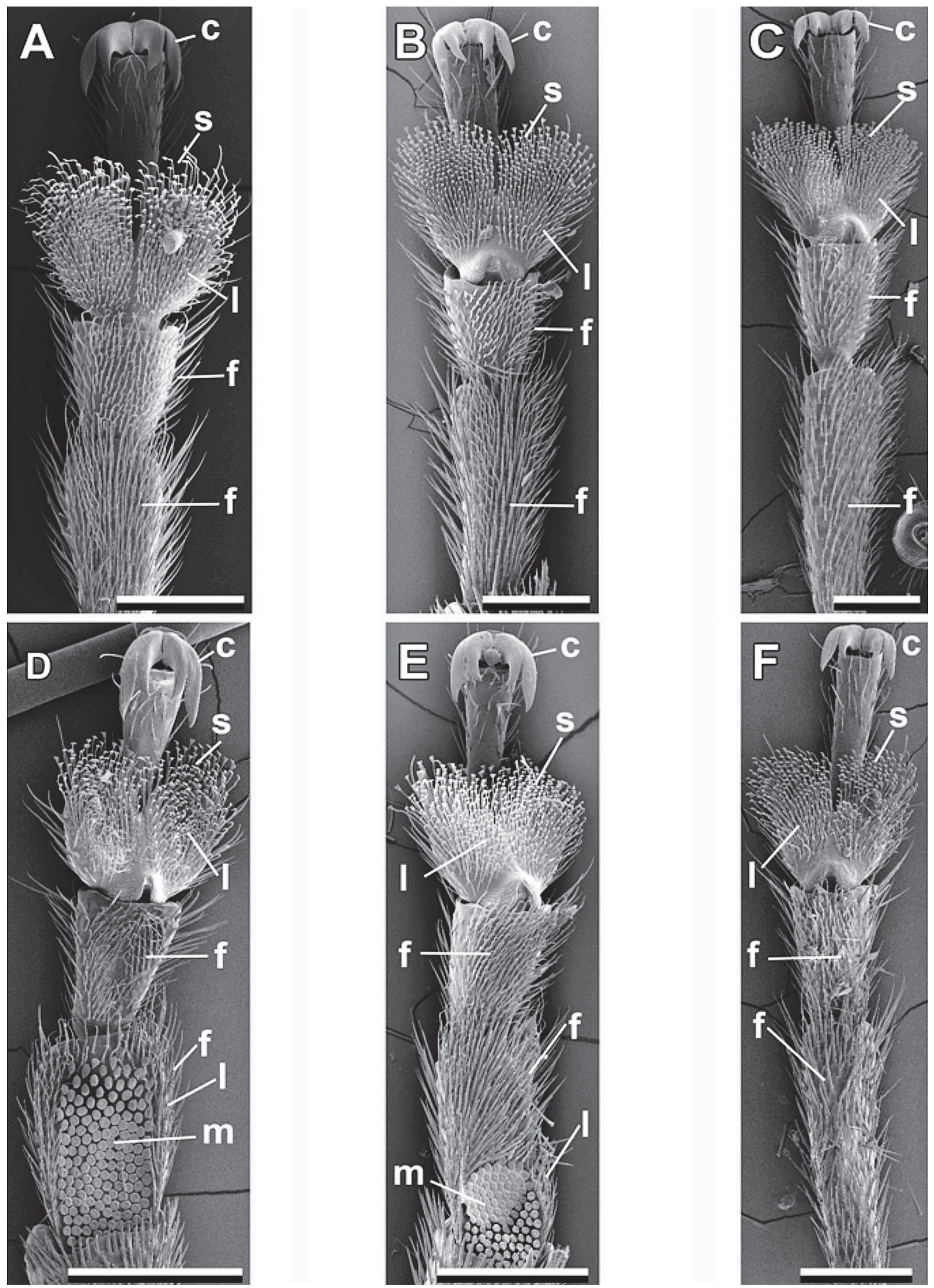

Fig. 1 SEM micrographs of the tarsi of Diabrotica virgifera. Female fore-( $(A)$, mid-(B) and hind-leg $(C)$; male fore-(D), mid-(E) and hind-leg $(F)$. $c$, claw; $S$, spatula-shaped setae; I, lanceolate setae; $f$, filamentous setae; $m$, setae with discoid terminal part; scale bars: $200 \mu \mathrm{m}$. 

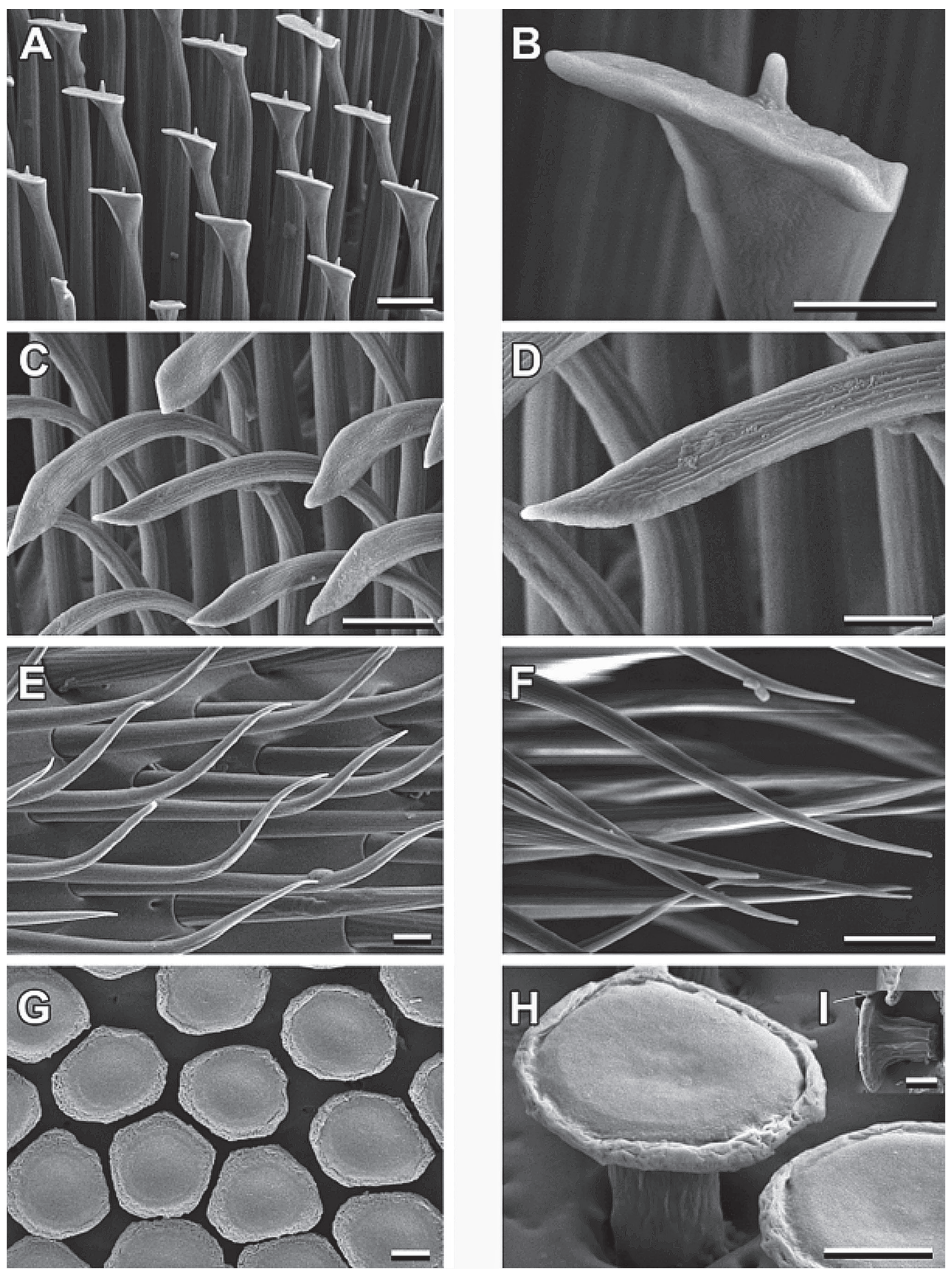

Fig. 2 SEM micrographs of tarsal adhesive setae of Diabrotica virgifera. A) spatula-shaped setae (female), B) detail of A) showing flattened tip with tooth-like protuberances dorsally; C) lanceolate setae (male), D) detail of C) showing flattend tapered tip; E) filamentous setae (male), F) detail of E) showing tapered tips; G) male-specific setae, H) detail of discoid terminal part of setae in $G$ ), I) laterally few of H); scale bars: $A, C, E, G, F, I=5 \mu$ m; $B, D, H=2 \mu m$. 
shapes of setae may indicate an adaptation for attaching to different surfaces. Further studies on the functional morphology may determine the significance of the sexual dimorphism in tarsal adhesive setae during the mating process and locomotion on plant substrates. In addition, a comprehensive knowledge of the attachment system of D. virgifera virgifera and its interaction with plant surfaces could potentially offer new ways of controlling this pest of crop plants.

\section{REFERENCES}

Aiken RB, Khan A (1992) The adhesive strength of the palettes of males of a boreal water beetle, Dytiscus alaskanus J. Balfour Browne (Coleoptera: Dytiscidae). Can J Zool 70: 1321-1324.

Baca F (1993) New member of the harmful entomofauna of Yugoslavia Diabrotica virgifera virgifera LeConte (Coleoptera: Chrysomelidae). IWGO Newsletter 13: 21-22.

Baufeld P (2014) The infestation situation of the western corn rootworm (Diabrotica virgifera virgifera) in Germany. Julius-Kühn-Archiv 44: 415.

Bechyné J (1956) Reise des Herrn G. Frey in Südamerika: Galerucidae (Col. Phytophaga). Entomologische Arbeiten aus dem $\mathrm{Mu}-$ seum Georg Frey Tutzing bei München 7: 241-358.

Bergsten J, Töyra A, Nilsson AN (2001) Intraspecific variation and intersexual correlation in secondary sexual characters of three diving beetles (Coleoptera: Dytiscidae). Biol J Linn Soc 73: 221-232.

Branson TF (1976) The selection of a non-diapause strain of Diabrotica virgifera (Coleoptera: Chrysomelidae). Entomol Exp Appl 19: 148-154.

Branson TF, Guss PL, Krysan JL, Sutter GR (1975) Corn rootworms: laboratory rearing and manipulation. USDA Agric Res Serv Bull 28: 1-18.

Breitenbach S, Gloyna K, Heimbach U, Thieme T, Dehne HW (2006) Getreidearten und Ungräser als alternative Wirtspflanzen der Larven von Diabrotica virgifera virgifera LeConte, 1868 (Coleoptera, Chrysomelidae). Mitt Dt Gesell Allg Angew Entomol 15: 257-258.

Gorb S (2001) Attachment devices of insect cuticle. Kluwer Academic Publishers, Dordrecht.

Gorb S (2005) Uncovering insect stickiness: structure and properties of hairy attachment devices. Am Entomol 5: 131-135.
Hammack L, French BW (2007) Sexual dimorphism of basitarsi in pest species of Diabrotica and Cerotoma (Coleoptera: Chrysomelidae). Ann Entomol Soc Am 100: 59-63.

Jackson JJ (1986) Rearing and handling of Diabrotica virgifera and Diabrotica undecimpunctata howardi. In: Krysan JL, Miller, TA (eds) Methods for the study of pest Diabrotica. Springer Series in Experimental Entomology 1, Springer-Verlag, New York, pp. 24-47.

Karlsson Green K, Kovalev A, Svensson EI, Gorb SN (2013) Male clasping ability, female polymorphism and sexual conflict: finescale elytral morphology as a sexually antagonistic adaptation in female diving beetles. J R Soc Interface 10: 1-10.

Kehlenbeck H (2014) Assessment of economic impacts of the western corn rootworm (Diabrotica virgifera virgifera) in Germany. Julius-Kühn-Archiv 444: 198-201.

Krysan JL (1986) Introduction: Biology, Distribution, and Identification of Pest Diabrotica. In: Krysan JL, Miller, TA (eds) Methods for the study of pest Diabrotica. Springer Series in Experimental Entomology 1, Springer-Verlag, New York, pp. 1-23.

Lew AC, Ball HJ (1979) The mating behavior of the western corn rootworm Diabrotica virgifera (Coleoptera: Chrysomelidae). Ann Entomol Soc Am 72: 391-393.

Miller KB (2003) The phylogeny of diving beetles (Coleoptera: Dytiscidae) and the evolution of sexual conflict. Biol J Linn Soc 79: 359-388.

Möser J (2003) Nutrional ecology of the invasive maize pest Diabrotica virgifera virgifera LeConte in Europe. $\mathrm{PhD}$ Thesis, Georg-August Universität, Göttingen.

Pelletier Y, Smilowitz Z (1987) Specialized tarsal hairs on adult male Colorado potato beetles, Leptinotarsa decemlineata (Say), hamper its locomotion on smooth surfaces. Can Entomol 119: $1139-1142$.

Prado LR (2013) Review on the use of sexually dimorphic characters in the taxonomy of Diabroticites (Galerucinae, Luperini, Diabroticina). ZooKeys 33: 233-254.

Stork NE, Evans MEG (1976) Tarsal setae in Coleoptera. Int J Ins Morphol Embryol 5: 219-221.

Stork NE (1980) A scanning electron microscope study of tarsal adhesive setae in the Coleoptera. Zool J Linn Soc 68: 173-306.

Stork NE (1983) Adaptations of arboreal carabids to life in trees. Acta Phytopathol Entomol Hung 22: 273-291.

Voigt D, Schuppert JM, Dattinger S, Gorb SN (2008) Sexual dimorphism in the attachment ability of the Colorado potato beetle Leptinotarsa decemlineata (Coleoptera, Chrysomelidae) to rough substrates. J Ins Physiol 54: 765-776. 